\title{
CORRESPONDENCE
}

\section{Recent trends in airway management: we are not ready to give up fiberoptic endoscopy [version 1; peer review: 3}

\section{approved]}

\section{Davide Cattano B), Rabail Chaudhry, Rashida Callender, Peter V Killoran, Carin A Hagberg}

Department of Anesthesiology, University of Texas Medical School at Houston, Houston, Texas, 77030, USA

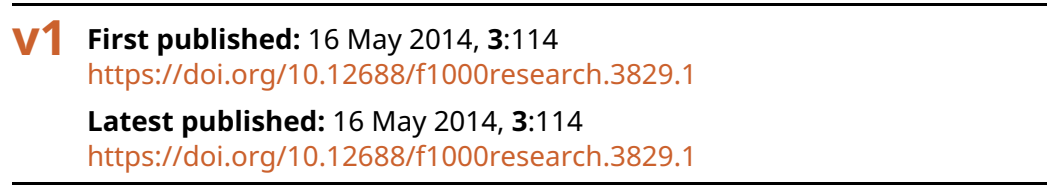

\section{Abstract}

The purpose of this correspondence is to discuss recent findings related to current trends in airway management and to discuss the utilization rates of video laryngoscopes versus traditional techniques in USA, UK, and Canada. To highlight the increased use of video laryngoscopes in difficult airway situations, data on the use of alternative airway devices at our institution collected from 2008 to 2010 are presented alongside the results of previously published surveys collected from 2002 to 2013.

\section{Open Peer Review \\ Approval Status

12 \\ 3 \\ version 1 \\ 16 May 2014

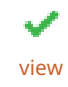 \\ view \\ view}

1. Sairam Parthasarathy, University of Arizona,

Tucson, AZ, USA

2. Suzanne Karan (D), University of Rochester

Medical Center, Rochester, NY, USA

3. Ronald Pearl, Stanford University Medical

Center, Stanford, CA, USA

Any reports and responses or comments on the article can be found at the end of the article. 
Corresponding author: Davide Cattano (Davide.Cattano@uth.tmc.edu)

Competing interests: Davide Cattano has received grant support from Karl Storz Endoskope Inc. Dr Cattano serves on the speaker bureau for Cadence and is a paid consultant for Smiths Medical. Dr Carin A. Hagberg has received grant support from AMBU, Covidien, and Karl Storz Endoskope Inc. She serves on the speaker bureau for Covidien, LMA North America, and Ambu A/S.

Grant information: The study was sponsored by an educational grant from the Foundation for Anesthesia Education and Research (FAER). Davide Cattano has received grant support from Karl Storz Endoskope Inc. Dr Carin A. Hagberg has received grant support from AMBU, Covidien, and Karl Storz Endoskope Inc.

The funders had no role in study design, data collection and analysis, decision to publish, or preparation of the manuscript.

Copyright: $\odot 2014$ Cattano D et al. This is an open access article distributed under the terms of the Creative Commons Attribution License, which permits unrestricted use, distribution, and reproduction in any medium, provided the original work is properly cited. Data associated with the article are available under the terms of the Creative Commons Zero "No rights reserved" data waiver (CC0 1.0 Public domain dedication).

How to cite this article: Cattano D, Chaudhry R, Callender R et al. Recent trends in airway management: we are not ready to give up fiberoptic endoscopy [version 1; peer review: 3 approved] F1000Research 2014, 3:114 https://doi.org/10.12688/f1 000 research.3829.1

First published: 16 May 2014, 3:114 https://doi.org/10.12688/f1000research.3829.1 


\section{Correspondence}

Education and research in anesthesia have increasingly focused on the management of difficult airways, leading to the development of new devices that are gradually becoming available and part of routine use across the globe. It is rather interesting to assess whether we have made much progress in using such devices over the past decade.

We read with great interest the letter 'Should we really consider to lay down the Macintosh laryngoscope?' ${ }^{\text {, }}$ in which Merli G. et al. discuss the present and future roles of video laryngoscopes and the continued value of older instruments, i.e. the Macintosh direct laryngoscope. We agree with the authors that over the past two decades, a large number of airway devices have been introduced into clinical practice.

Data from the early 2000s suggest that, despite the widespread availability of newer airway equipment, traditional techniques (direct laryngoscopy, laryngeal mask airway (LMA), and flexible fiberoptic endoscopy) were the preferred techniques for intubation (Table 1). Ezri et $a l .^{2}$ reported in 2003 that US attending anesthesiologists preferably used flexible fiberoptic endoscopy (75\%) for difficult airway management and preferred LMA (81\%) in failed intubation/ventilation scenarios. Similarly, in 2004, fiberoptic endoscopy $(64 \%)$ and some form of blind technique (26\%) were used by anesthesiologists in the $\mathrm{UK}^{4}$. In 2005, practitioners in Canada preferred fiberoptic endoscopy (34\%) and direct laryngoscopy $(48 \%)^{5}$. In most surveys, lack of availability and training with newer equipment was of concern ${ }^{2-5}$.

Table 1. Outcomes of surveys completed regarding the preference of alternative airway management devices by geographical area and year completed.

\begin{tabular}{|lll|}
$\begin{array}{l}\text { Geographical } \\
\text { area of survey }\end{array}$ & Year & Alternative device outcomes \\
\hline Canada $^{3}$ & 2002 & $\begin{array}{l}\text { Fiberoptic (34\%) and direct } \\
\text { laryngoscopy (48\%) }\end{array}$ \\
\hline USA $^{2}$ & 2003 & $\begin{array}{l}\text { Fiberoptic (75\%) for difficult airway } \\
\text { management LMA (81\%) in failed } \\
\text { intubation/ventilation scenarios }\end{array}$ \\
\hline $\begin{array}{l}\text { UK, Oxford } \\
\text { Region }\end{array}$ & 2004 & $\begin{array}{l}\text { Fiberoptic (64\%) and blind } \\
\text { technique (26\%) }\end{array}$ \\
\hline Canada $^{6}$ & 2013 & Video laryngoscope (90\%) \\
\hline
\end{tabular}

We analyzed the utilization rates of alternative airway devices using data collected between 2008 and 2010 at our institution, the University of Texas Medical School at Houston, Memorial Hermann Hospital - Texas Medical Center (Table 2).

The most commonly used alternative airway devices were oral fiberoptic intubation (OFOI), $(n=318$, usage rate $=3.69 \%$, first attempt success rate $=92.5 \%$ ), the Glidescope ${ }^{\circledR}$ video laryngoscopy system (Verathon Inc, USA), $(\mathrm{n}=223$, usage rate $=2.59 \%$, first attempt success rate $=95.5 \%$ ), the Storz C-MAC ${ }^{\circledR}$ video laryngoscopy system (Karl Storz, Germany), $(n=154$, usage rate $=1.79 \%$, first attempt
Table 2. Alternative airway device usage rates and first attempt success rates at our institution, Memorial Hermann Hospital Texas Medical Center at Houston, TX, USA: n, number of responders that prefer the use of a particular device for the majority of cases; usage rate, the percentage of responders that prefer the use of a particular device for the majority of cases; first attempt success rate, number of cases in which successful intubation was achieved in the first attempt.

\begin{tabular}{|c|c|c|c|}
\hline Alternative airway device & (n) & $\begin{array}{l}\text { Usage } \\
\text { rate }\end{array}$ & $\begin{array}{l}\text { First attempt } \\
\text { success rate }\end{array}$ \\
\hline Oral Fiberoptic (OFOI) & 318 & $3.69 \%$ & $92.5 \%$ \\
\hline $\begin{array}{l}\text { Glidescope }{ }^{\circledast} \text { video } \\
\text { laryngoscope (Verathon } \\
\text { Inc, USA) }\end{array}$ & 223 & $2.59 \%$ & $95.5 \%$ \\
\hline $\begin{array}{l}\text { Storz C-MAC }{ }^{\circledR} \text { video } \\
\text { laryngoscope (Karl Storz, } \\
\text { Germany) }\end{array}$ & 154 & $1.79 \%$ & $94.8 \%$ \\
\hline $\begin{array}{l}\text { Aintree intubation catheter } \\
\text { (Cook Critical Care, USA) }\end{array}$ & 106 & $1.23 \%$ & $96.2 \%$ \\
\hline Bougie & 92 & $1.07 \%$ & $85.9 \%$ \\
\hline Nasal fiberoptic (NFOI) & 92 & $1.07 \%$ & $85.9 \%$ \\
\hline
\end{tabular}

success rate $=94.8 \%$ ), the Aintree Intubation Catheter (Cook Critical Care, USA), $(\mathrm{n}=106$, usage rate $=1.23 \%$, first attempt success rate $=96.2 \%$ ), bougie $(n=92$, usage rate $=1.07 \%$, first attempt success rate $=95.7 \%)$ and nasal fiberoptic intubation (NFOI), $(n=92$, usage rate $=1.07 \%$, first attempt success rate $=85.9 \%$ ). Among these devices, OFOI and NFOI most likely required multiple intubation attempts, while the other devices had relatively high rates of success on the first intubation attempt.

When comparing our results with those obtained by Ezri et $a l .^{2}$, the most striking difference is the increased use of video laryngoscopes. Ezri et al., reported fiberoptic intubation and the LMA as the most popular in management of the difficult airway; no data was reported on the utilization rates of video laryngoscopes. The results of a similar survey completed by Canadian Anesthesiologists were recently presented at the Society of Airway Management Meeting 2013, where Mehta et al. ${ }^{6}$ showed that the preferred alternative airway technique in difficult intubation situations was video laryngoscope. In a 2005 survey $^{5}$ the same authors found that the preferred devices were lighted stylet, bronchoscope, and intubating laryngeal mask airway (Table 1).

There has been a rapid acceptance of video laryngoscopy as an important technique in the management of difficult airway situations. It is our opinion though, that while video laryngoscopy is preferred for ease of use and a faster learning curve, the technique of flexible fiberoptic endoscopy offers invaluable advantages: nasal and oral intubation, double lumen tube or bronchial blocker placement for thoracic surgery, therapeutic bronchoscopy, and it is preferred for awake technique intubation. The device versatility also makes it economical not to mention the greater value of education and training of future anesthesiologists. 


\section{Author contributions}

DC, PVK, and CAH initiated the study. RC and PVK performed the analysis. RC and RAC wrote the abstract and main body of the article. DC supervised the process. All authors critically edited the correspondence and agreed to the final content.

\section{Competing interests}

Davide Cattano has received grant support from Karl Storz Endoskope Inc. Dr Cattano serves on the speaker bureau for Cadence and is a paid consultant for Smiths Medical. Dr Carin A. Hagberg has received grant support from AMBU, Covidien, and
Karl Storz Endoskope Inc. She serves on the speaker bureau for Covidien, LMA North America, and Ambu A/S.

\section{Grant information}

The study was sponsored by an educational grant from the Foundation for Anesthesia Education and Research (FAER). Davide Cattano has received grant support from Karl Storz Endoskope Inc. Dr Carin A. Hagberg has received grant support from AMBU, Covidien, and Karl Storz Endoskope Inc.

The funders had no role in study design, data collection and analysis, decision to publish, or preparation of the manuscript.

\section{Supplementary materials}

Pre-operative assessment form and post-operative evaluation used in the survey on alternative airway devices at the Memorial Hermann Hospital - Texas Medical Center at Houston, TX, USA.

Pre-operative Airway Assessment Form pdf file.

Post-operative Evaluation pdf file.

1. Merli G, Guarino A, Petrini F, et al.: Should we really consider to lay down the Macintosh laryngoscope? Minerva Anestesiol. 2012; 78(9): 1078-9. PubMed Abstract

2. Ezri T, Szmuk P, Warters RD, et al.: Difficult airway management practice patterns among anesthesiologists practicing in the United States: have we made any progress? J Clin Anesth. 2003; 15(6): 418-22. PubMed Abstract | Publisher Full Text

3. Jenkins K, Wong DT, Correa R: Management choices for the difficult airway by anesthesiologists in Canada. Can J Anesth. 2002; 49(8): 850-6. PubMed Abstract | Publisher Full Text

4. Bokhari A, Benham SW, Popat MT: Management of unanticipated difficult intubation: a survey of current practice in the Oxford region. Eur $J$ Anesthesiol. 2004; 21(2): 123-7.

PubMed Abstract

5. Wong DT, Lai K, Chung FF, et al:: Cannot intubate-cannot ventilate and difficult intubation strategies: results of a Canadian national survey. Anesth Analg. 2005; 100(5): 1439-46.

PubMed Abstract | Publisher Full Text

6. Mehta A, Tam A, Yau B, et al.: Preferences of Canadian Anesthesiologists in difficult intubation and cannot intubate - cannot ventilate situations. Abstracts of Oral Presentations - Society of Airway Management Meeting. 2013. Publisher Full Text 


\section{Open Peer Review}

\section{Current Peer Review Status:}

\section{Version 1}

Reviewer Report 16 July 2014

https://doi.org/10.5256/f1000research.4102.r5326

(C) 2014 Pearl R. This is an open access peer review report distributed under the terms of the Creative Commons Attribution License, which permits unrestricted use, distribution, and reproduction in any medium, provided the original work is properly cited.

\section{Ronald Pearl}

Department of Anesthesia, Stanford University Medical Center, Stanford, CA, USA

This report from one of the leading institutions in airway management confirms the rapid growth in the use of alternative airway devices, especially video laryngoscopes, but emphasizes that, on one hand, the majority of patients are still intubated using direct laryngoscopy, and, on the other hand, there remains an important role for fiberoptic intubation. The report documents a large number of available alternative airway devices but does not address the issues of how many different devices are required for the potential range of airway issues and how many devices can the standard practitioner be trained to use and maintain competency in their use.

Competing Interests: No competing interests were disclosed.

I confirm that I have read this submission and believe that I have an appropriate level of expertise to confirm that it is of an acceptable scientific standard.

Reviewer Report 11 July 2014

https://doi.org/10.5256/f1000research.4102.r5327

(c) 2014 Karan S. This is an open access peer review report distributed under the terms of the Creative Commons Attribution License, which permits unrestricted use, distribution, and reproduction in any medium, provided the original work is properly cited.

\section{Suzanne Karan}

Department of Anesthesiology, University of Rochester Medical Center, Rochester, NY, USA

This article represents a growing body of research which will hopefully inform the appropriate 
education and training of our residents. The authors present data regarding the reported use of a variety of devices to manage the difficult airway. The venue of using F1000Research to quickly and more widely disseminate this information is highly valuable. The granularity of knowing user rate and first attempt success rate for these devices is a constructive addition that should be incorporated in future surveys to allow for comparison. With more data, it will be interesting to note whether the lower first attempt success for FOI (nasal or oral) stays the same or even drops compared with video laryngoscopy as the latter becomes more prevalently used and taught. The authors are commended in adding their research findings and their thoughtful opinions for review.

Competing Interests: No competing interests were disclosed.

I confirm that I have read this submission and believe that I have an appropriate level of expertise to confirm that it is of an acceptable scientific standard.

Reviewer Report 30 May 2014

https://doi.org/10.5256/f1000research.4102.r4807

(C) 2014 Parthasarathy S. This is an open access peer review report distributed under the terms of the Creative Commons Attribution License, which permits unrestricted use, distribution, and reproduction in any medium, provided the original work is properly cited.

\section{Sairam Parthasarathy}

Pulmonary, Allergy, Critical Care, and Sleep Medicine, University of Arizona, Tucson, AZ, USA

Excellent and insightful information about approaches to intubation

Competing Interests: No competing interests were disclosed.

I confirm that I have read this submission and believe that I have an appropriate level of expertise to confirm that it is of an acceptable scientific standard. 
The benefits of publishing with F1000Research:

- Your article is published within days, with no editorial bias

- You can publish traditional articles, null/negative results, case reports, data notes and more

- The peer review process is transparent and collaborative

- Your article is indexed in PubMed after passing peer review

- Dedicated customer support at every stage

For pre-submission enquiries, contact research@f1000.com 